\title{
Case Report of a Successful Delivery in a 29-Year-Old Female with History of Purandare Hysteropexy Surgery
}

\author{
I. Gede Mega Putra*, Riza Firman Satria, I. Wayan Megadhana, Kadek Fajar Marta, Ketut Surya Negara \\ Department of Obstetrics and Gynecology, Medical Faculty, Udayana University, Sanglah Hospital, Bali, Indonesia
}

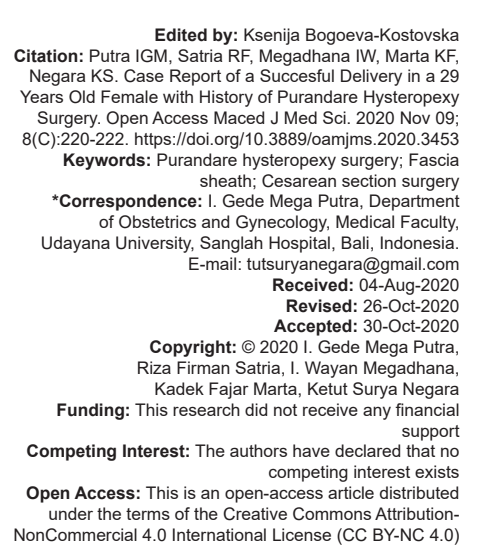

\section{Introduction}

Pelvic organ prolapse (POP) in young women is an uncommon case. Prolapse development is caused by multifactorial, with vaginal child birth, advancing age, and increasing body mass index as the most consistent risk factors. Vaginal delivery, hysterectomy, chronic straining, normal aging, and abnormalities of connective tissue or connective tissue repair predispose some women to disruption, stretching, or dysfunction of the levator ani complex, connective tissue attachments of the vagina, or both, resulting in prolapse [1], [2].

To reduce the number of women developing $\mathrm{POP}$, it is important to know the possible risk and protective factors. Some women with multiple risk factors never develop POP, whereas others with little or no risk factors develop POP, sometimes at young age. Bump and Norton were the first to describe a model for the development of pelvic floor dysfunctions. They categorize different risk factors into predisposing factors (e.g., hereditary factors and collagen distribution), inciting factors (e.g., vaginal delivery), promoting factors (e.g., obesity), and decompensating factors (e.g., aging) [3].
The prevalence of POP among young women is lower than older women, and the peak incidence of surgical intervention for POP among women is in patients age 60-70 years. Nygaard et al. investigated the prevalence of symptomatic pelvic floor disorders in American women found that POP in younger women is less common, with prevalence rate of $1.6 \%$ in women younger than 40 years compared to $3.8 \%$ in women age $40-59$ years. Strohbehn et al. found that young patients $<35$ years old undergoing surgery for POP had a higher prevalence of congenital anomalies, as well as neurological and rheumatological diseases. Rinne and Kirkinen evaluated POP in women younger than 45 years old found that increased number of deliveries, heavier babies, previous abdominal hernia operations, and chronic pulmonary diseases were risk factors for POP. Samuelsson et al. documented prolapse on pelvic examination in $30.8 \%$ of 487 premenopausal Swedish women (aged 20-59 years) [4], [5].

POP can be treated conservatively using intravaginal devices or surgery. The choice of treatment depends on symptoms, severity of prolapse, as well as patient and doctor preferences. The goals of surgery for POP include restoration of normal anatomy, to maintain or restore urinary, bowel, and sexual functions, and to improve quality of life. Uterine conservation is 
important for women who wish to preserve fertility and is seemingly associated with improvements in sexuality, confidence, and self-esteem. Women may also request preservation of the uterus due to personal beliefs or to retain a sense of identity, hence, recently, there has been much interest in preserving the uterus during prolapse surgery and an increasing number of women are requesting uterine conservation. Compared with hysterectomy and prolapse repair, hysteropexy is associated with a shorter operative time, less blood loss, and a faster return to work. Other advantages include maintenance of fertility, natural timing of menopause, and patient preference. Disadvantages include lack of long-term prolapse repair outcomes and the need to continue surveillance for gynecological cancers [6], [7].

There are various conservative surgical techniques for correcting POP, the selected one was purandare hysteropexy. This technique uses the native fascia of the patient itself as the media to support the uterus. Purandare hysteropexy technique is superior, especially for a young age woman who wants to have another pregnancy. At present, there is no literature that explains about pregnancy and delivery in patients with a history of purandare hysteropexy surgery [8].

The current case report presents the case of a delivery in a 29-year-old term pregnancy woman with a history of purandare hysteropexy surgery one year before. In this case report, the mode of delivery method was cesarean section with consideration not to undermine the conservative surgical that has been carried out previously which can result in recurrent POP. There will be discussions about fascia sheath evaluation during pregnancy and cesarean section surgery.

\section{Case Report}

A 29-year-old pregnant woman in her second pregnancy, with a history of purandare hysteropexy surgery within 1 year came to obstetric outpatient department to plan delivery with cesarean section. The patient went for the first pregnancy checkup at a private midwife practice with a positive pregnancy test at 10-11 weeks gestation, then started to check with an obstetrician. The patient complained of nausea, no injuries and no abdominal pain, and no bowel obstruction nor urination. In the second trimester, the patient did not complain of front abdominal pain, no bowel problem, and no urination disorder. She felt mild lower abdominal pain at 34 weeks gestational age. It increased when she strains and coughs, no disruption for her defecation, and micturition and the pain did not interfere with her activities. There were no changes in her micturition and defecation.
The history of previous illness, she complained a mass protruding from her vagina for the past 1 year. She complained the protruded mass started to disturb her work and sexual life for 1 month ago. There was no pattern change in her defecation and micturition, no history of chronic disease such as chronic cough or constipation, and no history of the same complaint within her family. She works as a construction worker for 5 months ago, $5 \mathrm{~h} /$ day. She had a normal vaginal delivery without any instrumentation in 2008. She denied any prolonged labor during her last delivery. From the gynecology examination and Valsalva maneuver, a mass protruded through the hymen was seen from the urogenital hiatus. The mass consists of the anterior, the posterior wall of vagina, and the uterus. The POP Quantification examination result was: $\mathrm{Aa}+1, \mathrm{Ba}+2, \mathrm{C}+4, \mathrm{Gh} 5, \mathrm{~Pb} 2$, TVL 7, Ap -2, $B p-1$, and $D+2$. The Pap smear was negative for intraepithelial lesion or malignancy. The patient was diagnosed with a cystocele Grade III, uterine prolapse Grade III, and rectocele Grade II. There are various studies about the intrinsic factors of POP, such as genetic factor involved in the pathophysiology. However, the gene involved in the pathophysiology still cannot be determined.

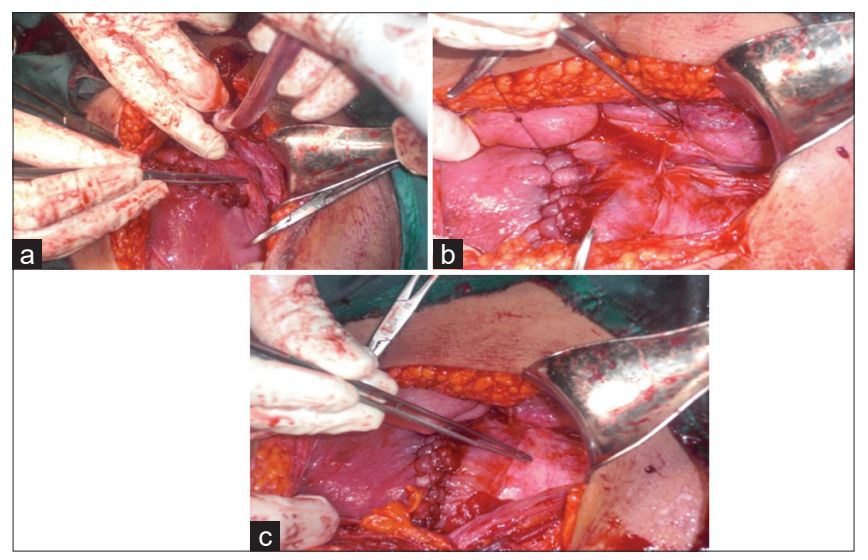

Figure 1: (a) Right abdominal fascia sheath, (b) left abdominal fascia sheath, (c) anterior abdominal fascia sheath covers lower uterine segment

During the previous antenatal care, the fascia sheath had been evaluated in her third trimester of pregnancy. The mode of delivery method was cesarean section with consideration not to undermine the conservative surgical that have been carried out previously which can result in recurrent POP. During surgery, there was no intra-abdominal adhesion and all sides of fascia sheath were well. Uterine incision is carried out above the anterior sheath because lower uterine segment is covered by anterior fascia sheath. The outcome was a baby boy, weighted 2900 $\mathrm{g}$, body length $49 \mathrm{~cm}$ with good Apgar score and postoperative care was good. There was no disruption in her micturition and defecation, she was well mobilized and treatment was continued by outpatient care in the following days (Figures 1 and 2). 


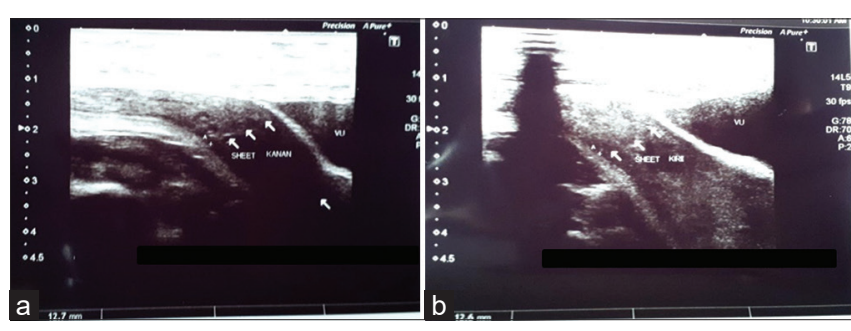

Figure 2: (a) Right fascia sheath $12.7 \mathrm{~mm}$ from urinary bladder (b) left fascia sheath $12.6 \mathrm{~mm}$ from urinary bladder

\section{Discussion}

There are many suspension or sling operations which have been designed for the young woman suffering from the second or third degree prolapse and who desire to retain their childbearing and menstrual functions. Such suspension is called hysteropexy when uterine body is suspended with the ligamentous or bony supports and cervicopexy when the cervix is held up with the help of slings or tapes. Purandare hysteropexy surgery technique used the native fascia of the patient itself as the media to support the uterus. A fascia band created from rectus sheath was used, which was fixed to the anterior surface of the uterus. It has comparable outcome of up to $90 \%$ when compared to difficult technically procedures such as sacrospinous hysteropexy and sacral hysteropexy [8], [9], [10].

Pregnancy and delivery in patient with a history of purandare hysteropexy surgery is a rare case. At present, there is no literature of pregnancy women and the mode of delivery that is effective in patients with history of purandare hysteropexy surgery. In this case report, the mode of delivery method is cesarean section with consideration not to undermine the conservative surgical that has been carried out previously. Before surgery, fascia sheath is evaluated in the third trimester to determine the incision location during cesarean section surgery to avoid the fascia sheath, to determine the possibility of adhesion, and to evaluate the possibility of fascia sheath rupture that can occur during pregnancy.

\section{Summary}

This case reports a 29-year-old second term pregnancy woman with a history of purandare hysteropexy surgery 1 year ago. She had a full-term gestational age, during cesarean section, surgery intraabdominal adhesion was not seen and all sides of fascia sheath were in a good condition, and the outcome was a baby with good condition. It is a rare case and there is no case report study which has been reported previously.

At present, there is no literature of pregnancy and the mode of delivery that is effective in patients with a history of purandare hysteropexy surgery. We recommend delivery by cesarean section to minimize the risk of damage of the post-operative purandare hysteropexy surgery anatomical structure.

We think that purandare hysteropexy surgery may be considered as a first choice for conservative treatment of uterovaginal prolapse for women in reproductive age group who wish to retain their capacity for childbearing as it is relatively simple, short duration of operation, and also good result from the anatomy and functionally.

In the $5^{\text {th }}$ month after the surgery, the patient complained that she urinated when coughed up, sneezed, and pushed, but she could hold urination when she had the urge until she reached toilet. She also felt a lump at anterior and posterior vagina. The lumps are in a marble size, painless, and felt enlarged when urinating, coughing, pushing, and decreased when she rested. Yet, she refused to have surgery done.

\section{References}

1. Strohbehn K, Jakary JA, Delancey JO. Pelvic organ prolapse in young women. Obstetr Gynecol. 1997;90(1):33-6. https://doi. org/10.1016/s0029-7844(97)00218-4 PMid:9207808

2. Jelovsek JE, Maher C, Barber MD. Pelvic organ prolapse. Lancet. 2007;369(9566):1027-38.

PMid: 17382829

3. Lince LS, van Kempen LC, Vierhout ME, Kluivers KB. A systematic review of clinical studies on hereditary factors in pelvic organ prolapse. Int Urogynecol J. 2012;23(10):1327-36. https://doi.org/10.1007/s00192-012-1704-4 PMid:22422218

4. Alcalay M, Stav K, Eisenberg VH. Family history associated with pelvic organ prolapse in young women. Int Urogynecol J. 2015;26(12):1773-6.

PMid:26174658

5. Kim S, Harvey MA, Johnston S. A review of the epidemiologi and pathofisiology of pelvic floor dysfunction: Do racial differences matter? J Obstet Gynaecol Can. 2005;27(3):251-9.

PMid:15937599

6. Guldberg R. Clinical epidemiological studies of women undergoing surgery for urogynaecological disorders. Dan Med J. 2015;62(10):B5154.

PMid:26441398

7. Cilgin $\mathrm{H}$. Laparoscopic Uterine Conservation in Uterovaginal Prolapse. United States: Advanced Laparoscopy; 2017.

8. Putra IG, Kawilarang S. Purandare histeropexy technique in a 28 year old female with pelvic organ prolapse stage III: A rare case report. Bali Med J (Bali Med). 2016;5(3):385-7. https://doi. org/10.15562/bmj.v5i2.256

9. Rameshkumar R, Kamat L, Tungal S, Moni S. Modified Purandare's cervicopexy-a conservative surgery for genital prolapse: A retrospective study. Int J Reprod Contracept Obstet Gynecol. 2017;6(5):1777-81. https://doi.org/10.18203/23201770.jircog20171529

10. Nagrath A, Malhotra N. Uterus Displacement: A Colour Atlas of Cervicopexy Purandares (Single Surgical Procedures in Obstetrtrics and Gynaecology). Tamil Nadu: Jaypee Brothers Medical Pub; 2012. p. 2-3. https://doi.org/10.5005/jp/books/11506_5 